\title{
The effects of eating marine- or vegetable-fed farmed trout on the human plasma proteome profiles of healthy men
}

\author{
Maria L. Rentsch ${ }^{1}$, René Lametsch ${ }^{2}$, Susanne Bügel ${ }^{3}$, Flemming Jessen ${ }^{1}$ and Lotte Lauritzen ${ }^{3 *}$ \\ ${ }^{1}$ Division of Industrial Food Research, National Food Institute, Technical University of Denmark, Lyngby, Denmark \\ ${ }^{2}$ Department of Food Science, Faculty of Science, University of Copenhagen, 1958 Frederiksberg C, Denmark. \\ ${ }^{3}$ Department of Nutrition, Exercise and Sports, Faculty of Science, University of Copenhagen, Rolighedsvej 26, \\ 1958 Frederiksberg C, Denmark \\ (Submitted 17 March 2014 - Final revision received 30 October 2014 - Accepted 12 November 2014 - First published online 27 January 2015)
}

\section{Abstract}

Most human intervention studies have examined the effects on a subset of risk factors, some of which may require long-term exposure. The plasma proteome may reflect the underlying changes in protein expression and activation, and this could be used to identify early risk markers. The aim of the present study was to evaluate the impact of regular fish intake on the plasma proteome. We recruited thirty healthy men aged 40 to 70 years, who were randomly allocated to a daily meal of chicken or trout raised on vegetable or marine feeds. Blood samples were collected before and after 8 weeks of intervention, and after the removal of the twelve most abundant proteins, plasma proteins were separated by two-dimensional gel electrophoresis. Protein spots $<66 \mathrm{kDa}$ with a pI $>4.3$ visualised by silver staining were matched by two-dimensional imaging software. Within-subject changes in spots were compared between the treatment groups. Differentially affected spots were identified by matrix-assisted laser desorption ionisation-time of flight/time of flight MS and the human Swiss-Prot database. We found 23/681 abundant plasma protein spots, which were up- or down-regulated by the dietary treatment $(P<0 \cdot 05, q<0 \cdot 30)$, and eighteen of these were identified. In each trout group, ten spots differed from those in subjects given the chicken meal, but only three of these were common, and only one spot differed between the two trout groups. In both groups, the affected plasma proteins were involved in biological processes such as regulation of vitamin A and haem transport, blood fibrinolysis and oxidative defence. Thus, regular fish intake affects the plasma proteome, and the changes may indicate novel mechanisms of effect.

\section{Key words: Dietary interventions: Plasma proteomics: $n$-3 PUFA: Cardiovascular risk: Aquaculture fish production}

The American Heart Association now recommends increased intake of oily fish and/or fish oil supplementation ${ }^{(1)}$, as regular fish consumption has been shown to be associated with human health benefits, especially with a reduced risk of $\mathrm{CVD}^{(2)}$. These beneficial effects have been ascribed to the high content of $n-3$ long-chain PUFA (LC-PUFA), EPA and DHA, in fish ${ }^{(2-4)}$. A number of mechanisms have been proposed to explain the cardioprotective role of $n$ - 3 LC-PUFA including a substantial reduction in TAG concentration ${ }^{(5)}$, lower blood pressure level ${ }^{(6)}$ and heart rate ${ }^{(7)}$, improved vascular function ${ }^{(8)}$, and reduced tendencies for ventricular fibrillation $^{(7)}$, thrombosis ${ }^{(9)}$ and inflammation ${ }^{(10)}$. However, more recent studies have indicated that the protein component of fish may also have influences on health ${ }^{(11,12)}$, making it more complicated to investigate the effects of interventions with whole fish, as opposed to fish oil.
Most randomised dietary trials have investigated the effect of the intervention on a subset of risk factors; however, it may be useful to adopt more holistic exploratory approaches. Proteome analysis of human bio-fluids offers a strong approach to increase the understanding of the dynamic changes induced by dietary components ${ }^{(13)}$. These proteins may reflect changes in protein expression and activation, and serve as candidate biomarkers of health risk. Thus, the plasma proteome approach could potentially reveal early indicators of disease ${ }^{(13,14)}$, and contribute to the understanding of the mechanistic aspects of dietary health effects.

Increasing quantities of fish for human consumption are being produced by aquaculture. In aquaculturing, carnivorous fish species are typically grown on feed containing significant amounts of fishmeal and fish oil, and farming of carnivorous fish can require up to two to five times as much fish biomass input as the amount of fish produced ${ }^{(15)}$. Substantial effort has

Abbreviations: 2DE, two-dimensional electrophoresis; LC-PUFA, long-chain PUFA; MALDI TOF/TOF MS, matrix-assisted laser desorption ionisation-time of flight/time of flight MS.

*Corresponding author: L. Lauritzen, fax + 4535332483 , email ll@nexs.ku.dk 
been spent on evaluating different feed components of plant origin as alternatives to fishmeal and fish oils; this poses several barriers including anti-nutritional factors that may have adverse effects on diet utilisation and digestibility and thus on growth performance ${ }^{(16)}$. Furthermore, changes in feed composition may affect the nutritional value of the fish produced. Replacing fish oils with vegetable oils such as linseed and rapeseed has been shown to decrease the content of $n-3$ LC-PUFA in Atlantic salmon fish fillets ${ }^{(17,18)}$. The resulting effects on human health are largely unknown; however, one study on patients with CHD has shown that dietary intake of differently fed salmon influenced plasma TAG concentration and clinical markers of atherosclerosis ${ }^{(18)}$.

The overall objective of the present randomised, parallel, 8-week intervention study was to investigate the effects of dietary intake of farmed trout fed marine- or vegetablebased feeds compared with those of a reference meal of chicken in healthy elderly men; the main results of the study have already been published ${ }^{(19)}$. The present study evaluates the impact of the intake of these two types of trout relative to that of chicken on the human plasma proteome. The aim of the present sub-study was to quantify the differences in the abundance of plasma proteins after an 8-week intervention with a daily meal of marine-fed trout, vegetable-fed trout or a reference meal of chicken in thirty healthy men.

\section{Materials and methods}

\section{Study design and subjects}

As described previously ${ }^{(19)}$, we recruited sixty-eight apparently healthy men aged 40 to 70 years with no history of CVD, inflammatory disease, diabetes or other significant medical history, and with no regular medication (antiinflammatory, anti-hypertensive or lipid-lowering drugs). Furthermore, the subjects had to have a blood pressure $<160 / 100 \mathrm{mmHg}$, a BMI of $20-30 \mathrm{~kg} / \mathrm{m}^{2},<7 \mathrm{~h} /$ week strenuous exercise and $<7$ cigarettes/week; in addition, they were not allowed to take fish oil supplements. Group allocation was performed by assigning to each individual an identification number with a masked coupling to meal type. In this way, the subjects were randomly assigned to consume for 8 weeks a daily meal of $150 \mathrm{~g}$ farmed trout raised either on a pure marine diet (marine trout) or a pure vegetable diet (vegetable trout), or a reference meal of $150 \mathrm{~g}$ chicken.
The trout and chicken meals were identical except for the intervention ingredient, trout or chicken, and the addition of $3.5 \mathrm{~g}$ rapeseed oil to the chicken meals to compensate for differences in the fat content of the products. The meals provided were isoenergetic with a mean energy content of $1856 \mathrm{~kJ}$ and macronutrient contribution of $37 \mathrm{~g}$ protein, $26 \mathrm{~g}$ carbohydrate and $22 \mathrm{~g}$ fat. The fatty acid compositions, SFA, MUFA and PUFA as well as the $n-6: n-3$ PUFA ratio, of the intervention components of the meals were as follows: marine trout -25 , $32,36 \%$ and $0 \cdot 2$; vegetable trout $-15,52,30 \%$ and 1.5 ; chicken including the added rapeseed oil - 21, 47, 32\% and $3 \cdot 3$, respectively. The subjects were instructed to maintain their habitual diets and lifestyle throughout the study period, and to avoid any seafood except the one provided as part of the intervention meals.

All subjects gave their written informed consent to the study, which was conducted according to the guidelines laid down in the Declaration of Helsinki, and approved by the Local Research Ethical Committee of Copenhagen and Frederiksberg (H-KF 325441), and registered at ClinicalTrials. gov (NCT00432952).

\section{Blood sampling and preparation}

For the study, the volunteers visited the department for clinical examination at the beginning (week 0 ) and at the end of the intervention period (week 8). The participants consumed a standardised low-fat meal (maximum $15 \mathrm{~g}$ of fat), the evening before blood collection. A $12 \mathrm{~h}$ fasting blood sample in EDTA tubes was collected in the morning after $15 \mathrm{~min}$ of rest. Plasma was prepared directly after blood collection, to minimise the effect of pre-analytical variables on the proteome profiling. Blood samples were centrifuged at $2000 \mathrm{~g}, 21^{\circ} \mathrm{C}$ for $10 \mathrm{~min}$, following centrifugation at $3000 \mathrm{~g}, 21^{\circ} \mathrm{C}$ for $10 \mathrm{~min}$, to clear cellular debris; plasma was subsequently frozen in $1 \mathrm{ml}$ aliquots at $-80^{\circ} \mathrm{C}$ until analysis.

Samples from thirty (characterised in Table 1) of the sixty-eight subjects (both week 0 and week 8 samples from ten subjects from each intervention group) were randomly selected for proteomic analysis. To increase the resolution of the two-dimensional electrophoresis (2DE), the defrosted plasma samples were fractionated in random order by a ProteomeLab IgY-12 affinity spin column (Beckman Coulter), which in a reproducible way removed the twelve major abundant plasma proteins (albumin, $\alpha 1$-antitrypsin, IgA, IgG,

Table 1. Baseline characteristics of the subjects from each of the three meal groups (Mean values and standard deviations)

\begin{tabular}{|c|c|c|c|c|c|c|}
\hline \multirow{2}{*}{$\begin{array}{l}\text { Meal groups... } \\
\text { Variables }\end{array}$} & \multicolumn{2}{|c|}{$\begin{array}{l}\text { Marine trout } \\
\quad(n 10)\end{array}$} & \multicolumn{2}{|c|}{$\begin{array}{l}\text { Vegetable } \\
\text { trout }(n 10)\end{array}$} & \multicolumn{2}{|c|}{$\begin{array}{c}\text { Chicken } \\
(n 10)\end{array}$} \\
\hline & Mean & SD & Mean & SD & Mean & SD \\
\hline Age (years) & 48 & $6 \cdot 5$ & 56 & 5.9 & 50 & $6 \cdot 5$ \\
\hline Height $(\mathrm{cm})$ & 179 & $4 \cdot 8$ & 179 & $5 \cdot 1$ & 182 & 4.0 \\
\hline Weight (kg) & 78 & 9.4 & 81 & 9.0 & 85 & $7 \cdot 6$ \\
\hline BMI $\left(\mathrm{kg} / \mathrm{m}^{2}\right)$ & 25 & $2 \cdot 6$ & 25 & $2 \cdot 8$ & 26 & $2 \cdot 3$ \\
\hline Systolic blood pressure (mmHg) & 120 & $7 \cdot 7$ & 124 & 4.6 & 128 & $11 \cdot 0$ \\
\hline Diastolic blood pressure $(\mathrm{mmHg})$ & 77 & 5.4 & 80 & 1.9 & 81 & $7 \cdot 8$ \\
\hline
\end{tabular}


IgM, transferrin, haptoglobin, $\alpha 1$-acid glycoprotein, $\alpha 2$-macroglobulin, apoA-I and A-II, and fibrinogen) ${ }^{(20)}$. The depleted flow-through pool of plasma proteins was precipitated for $30 \mathrm{~min}$ on ice by TCA $(15 \%, \mathrm{w} / \mathrm{v})$. The samples were then centrifuged $\left(15000 \mathrm{~g}, 15 \mathrm{~min}\right.$ at $\left.4^{\circ} \mathrm{C}\right)$, and the pellets were washed twice by the addition of ice-cold $90 \%(\mathrm{v} / \mathrm{v})$ acetone followed by centrifugation $\left(15000 \mathrm{~g}, 5 \mathrm{~min}\right.$ at $\left.4^{\circ} \mathrm{C}\right)$

\section{Two-dimensional electrophoresis}

The precipitated plasma proteins (approximately $130 \mu \mathrm{g}$ ) were dissolved in $8 \mathrm{~m}$-urea, $2 \mathrm{~m}$-thiourea, $50 \mathrm{~mm}$-dithiothreitol, $1.5 \%$ 3-[(3-cholamidopropyl)dimethylammonio]-1-propanesulfonate (CHAPS), 1\% Pharmalyte 4-6.5, 1\% Pharmalyte $5-8,10 \mathrm{~mm}-$ Tris- $\mathrm{HCl}(\mathrm{pH} 8.3$ ) and orange-G in a total of $350 \mu \mathrm{l}$, and applied to Immobiline Drystrips (linear $\mathrm{pH} 4-7$ and length $18 \mathrm{~cm}$ ) by in-gel rehydration overnight. Isoelectric focusing was carried out at $20^{\circ} \mathrm{C}$ using a Multiphor flatbed (Amersham Biosciences), and proteins were separated for a total of $60000 \mathrm{Vh}$. The one-dimensional strip was stored at $-80^{\circ} \mathrm{C}$ until use.

The one-dimensional strip was reduced in equilibration solution (6 M-urea, 50 mm-Tris- $\mathrm{HCl}(\mathrm{pH} 8.8), 30 \%(\mathrm{v} / \mathrm{v})$ glycerol and $2 \%(\mathrm{w} / \mathrm{v})$ SDS) containing $1 \%(\mathrm{w} / \mathrm{v})$ dithiothreitol for $20 \mathrm{~min}$, and then alkylated in equilibration solution containing $4.5 \%(\mathrm{w} / \mathrm{v})$ iodoacetamide and a trace of bromophenol blue for $20 \mathrm{~min}$. The proteins were separated in the second dimension on $12 \%(\mathrm{w} / \mathrm{v})$ SDS-PAGE gels $(19 \mathrm{~cm} \times 23 \mathrm{~cm})$ according to their molecular weight. The one-dimensional strip was loaded on top of the gel with $0.5 \%(\mathrm{w} / \mathrm{v})$ agarose in $25 \mathrm{~mm}$-Tris- $\mathrm{HCl}(\mathrm{pH} 8.4), 192 \mathrm{~mm}-$ glycine and $0 \cdot 1 \%(\mathrm{w} / \mathrm{v})$ SDS. Gels from the different subjects were run randomly in batches of ten gels vertically in the Hoefer DALT System (Amersham Biosciences) at $12^{\circ} \mathrm{C}$ with a maximum current of $40 \mathrm{~mA} / \mathrm{gel}$.

\section{Gel staining and image analysis}

Protein spots of analytical gels were visualised by silver staining as described previously ${ }^{(21)}$. The gels were digitally imaged using a 16-bit charge-coupled device camera (Camilla; Raytest) and converted into tagged image file format files. The two-dimensional image analysis software 'Progenesis SameSpots' (version 3.3; Nonlinear Dynamics) was used for quantifying the differences in the abundance of plasma proteins. The reference gel was assigned to the gel with most spots detected. Spot detection was accomplished by manually defining a number of anchor spots, followed by automated warping of the gel images. The spot outlines from the reference gel were applied to all gels, producing data with no missing values. The matching of all spots was checked and manually edited, if necessary, thus eliminating the artifacts in the gel. Spot volumes were normalised by the built-in algorithm of Progenesis SameSpots, which is based on a spot volume abundance ratio between gels. All significant differentially abundant spots were localised in a clearly focused area of the gel, reflecting high-quality spots, i.e. consistent shape, non-saturation and proper splitting.

\section{Matrix-assisted laser desorption ionisation-time of flight/time of flight MS}

An attempt was made to identify protein spots that were differentially affected in the three diet groups by matrixassisted laser desorption ionisation-time of flight/time of flight (MALDI TOF/TOF) MS (4800 Plus Analyzer; Applied Biosystems). Preparative 2DE gels were run using adequate amounts of protein $(500 \mu \mathrm{g})$ for MS/MS peptide sequencing. The gels were silver-stained in an MS-compatible way, using a protocol without glutaraldehyde adapted from Shevchenko et $a{ }^{(22)}$. The proteins of interest were manually excised from the 2DE gel with a spot picker (The Gel Company), washed twice with 50\% acetonitrile and reduced with $10 \mathrm{~mm}$-dithiothreitol in $100 \mathrm{~mm}-\mathrm{NH}_{4} \mathrm{HCO}_{3}$ for $45 \mathrm{~min}$ at $56^{\circ} \mathrm{C}$. Subsequently, the spots were alkylated with 55 mm-iodoaceta-

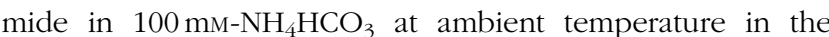
dark for $30 \mathrm{~min}$. Gel pieces were washed with $50 \%$ acetonitrile two times and left to re-swell in $12.5 \mathrm{ng} / \mu \mathrm{l}$ of trypsin (trypsin gold, MS grade; Promega) in digestion buffer $(50 \mathrm{~mm}-$ $\mathrm{NH}_{4} \mathrm{HCO}_{3}$ ) on ice for $45 \mathrm{~min}$. Excess trypsin solution was removed, and the in-gel proteins were digested with digestion buffer at $37^{\circ} \mathrm{C}$ overnight. The tryptic digest was desalted, concentrated and purified before MS analysis on microcolumns (POROS R2 resin) packed in GELoader pipette tips (Eppendorf AG) according to Gobom et $a l^{(23)}$. The peptide mixture was loaded onto the column and washed with $0 \cdot 1 \%$ trifluoroacetic acid. Peptides were eluted with $0 \cdot 8 \mu \mathrm{l}$ matrix solution $(5 \mu \mathrm{g} / \mu \mathrm{l}$ of $\alpha$-cyano-4-hydroxy-cinnamic acid in $70 \%(\mathrm{v} / \mathrm{v})$ acetonitrile/0.1\% (v/v) trifluoroacetic acid), and spotted onto the MALDI target for crystallisation. Peptide sequencing was obtained by the MALDI TOF/TOF operating in a positive-ion reflector mode. Spectra were externally calibrated with the standard tryptic digest of $\beta$-lactoglobulin in $0.1 \%$ trifluoroacetic acid, and internally calibrated with two ions derived from trypsin auto-digestion at $m / z 842.5$ and $2211 \cdot 1$.

\section{Database search}

Protein identification was exclusively based on MS/MS spectra. Peak lists were extracted from raw data using the software Data Explorer (version 4.6; Applied Biosystems), in which all spectra from an individual spot were fused into a single generic file. The search was performed with the search engine MASCOT (http://www.matrixscience.com) using the Swiss-Prot database restricted to Homo sapiens species. MS/MS search results are based on the following parameters: trypsin allowing one missed cleavage; carbamidomethyl on cysteine as fixed modification and oxidation of methionine as partial modification; peptide mass tolerance was set at 70 parts per million; fragment mass tolerance at $0.5 \mathrm{Da}$; peptide charged state as $1+$. Only probability scores $P<0.05$ were considered. Protein identities from the peptide summary report based on 1-6 peptides with a mean mass accuracy of 12 parts per million are shown in Table 2 (see online supplementary Table S1, which also contains information on the peptide sequences). 
Table 2. MS/MS-based identification and characterisation of human plasma proteins that changed in abundance after 8 weeks of dietary intervention*

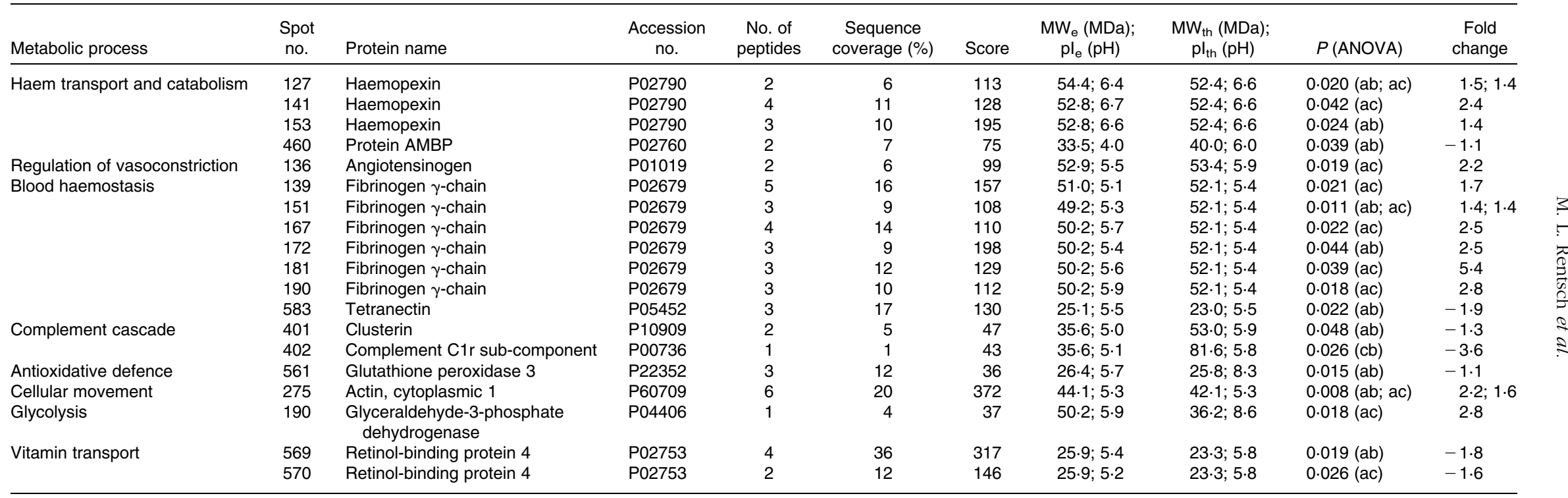

* The spatial distribution of the identified protein spots is marked on the gel in Fig. 1. Protein identification was accomplished by matrix-assisted laser desorption ionisation-time of flight/time of flight MS and accession numbers are given according to SwissProt/TrEMBL. The table lists the numbers of peptides, sequence coverages, spot identification scores as well as identified and theoretical molecular weights ( $M$ Da, $\mathrm{MW}_{\mathrm{e}}$ and $\mathrm{MW}_{\mathrm{th}}$, respectively) and isoelectric points ( $\mathrm{pH}, \mathrm{pl}_{\mathrm{e}}$ and $\mathrm{pl}_{\mathrm{th}}$, respectively) of the protein of interest. Spot 190 was found to represent two proteins: fibrinogen $\gamma$-chain and glyceraldehyde 3-phosphate dehydrogenase. The indicated $P$ values show the levels of found to differ (a, chicken (control); $b$, marine-fed trout; $c$, vegetable-fed trout), and a column to indicate the size of the difference as fold changes in a positive or negative direction relative to the chicken or vegetable trout group.
forich 


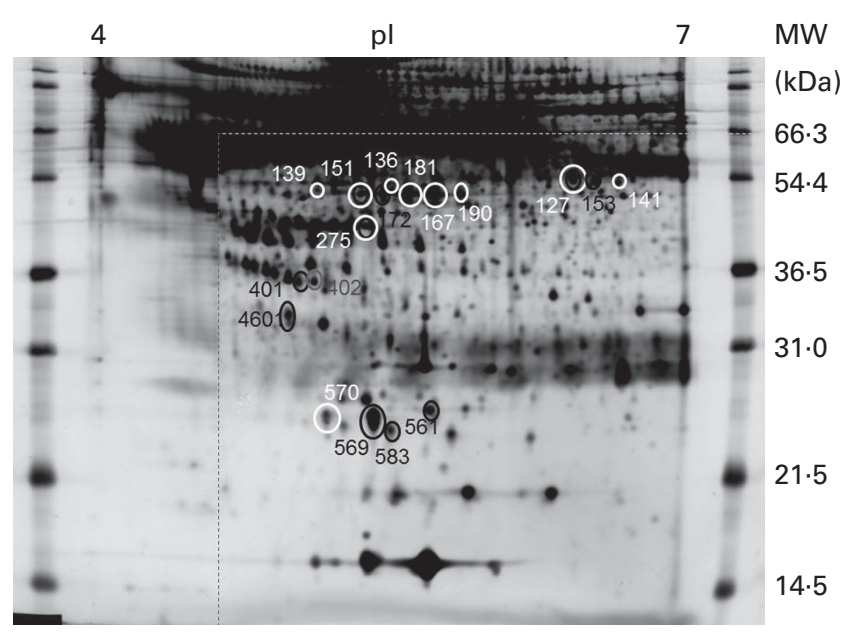

Fig. 1. Representative two-dimensional electrophoresis gel of plasma proteins from healthy men. The shown gel is from a subject in the chicken group at baseline (week 0), and is representative of the baseline samples. The stippled lines mark the area within which the spots were matched and compared across the diet groups. The spatial distribution of the eighteen identified protein spots that are differentially changed is marked on the gel in a way that shows how they change in abundance after an 8-week intervention with marine trout, vegetable trout or chicken diet (white: marine-fed trout $v$. chicken; black: vegetable-fed trout $v$. chicken; grey: marine $v$. vegetable-fed trout). The spot numbers correspond to those in Table 2. MW, molecular weight.

\section{Statistical analysis}

Normalised spot volumes of the 2DE data were extracted from the image analysis software 'Progenesis SameSpots' (Nonlinear Dynamics) and log-transformed before statistical data analysis. To reduce the inter-individual variation, normalised spot volumes were baseline-subtracted (i.e. the spot volumes at the end of the intervention period (week 8) subtracted the baseline volume (week 0)) and denoted delta spot volumes. These volumes were used for the following statistical analysis performed with the statistical software package SigmaStat (version 3.1; Aspire Software International). To identify the difference in protein abundance between samples from subjects who had consumed marine trout, vegetable trout or chicken, the delta spot volumes were examined spot by spot with one-way ANOVA $(P<0.05)$ followed by a pairwise post hoc test. The $q$ values of the respective differentially abundant proteins were calculated using the software package Q-value (version 1) that estimates the expected proportion of false positives for different $P$ value cut-offs based on the $P$ value distribution ${ }^{(24)}$. The computed $q$ values were based on the smoother method as proposed in Storey \& Tibshirani ${ }^{(24)}$. For proteins that were found to differ between groups, we calculated the effect size relative to the control group (chicken) as fold changes in a positive or negative direction (higher or lower in the group that had consumed trout, respectively). However, when spots from the subjects who had consumed the vegetable-fed trout were found to differ significantly from those of the subjects who had consumed the marine-fed trout, fold changes were calculated in a similar way relative to the vegetable trout.

A principal component analysis was conducted to visualise the correlations between differentially changed protein spots and erythrocyte fatty acids, previously found to be affected by the intervention ${ }^{(19)}$. Meal group was included in the principal component analysis as a pacified categorical variable, with no influence on the principal component analysis.

\section{Results}

The intervention did not result in any overall differences between the groups with respect to energy intake and dietary macronutrient composition, but did result in changes in the erythrocyte content of PUFA in the subjects, which were in accordance with what was expected, based on the fatty acid composition of the farmed trout and the chicken ${ }^{(19)}$.

After the removal of the top twelve most abundant proteins, the 2DE (see Fig. 1) analysis of plasma proteins revealed a total of 681 distinctly separated high-quality silver-stained protein spots, which were matched and compared between gels. A fraction of spots on the two-dimensional gel was not included in the pool of the 681 spots due to artifacts in the gel, i.e. smear, especially in the area of high-molecular-weight proteins. The included spots covered a molecular weight of $14-66 \mathrm{kDa}$ and a $\mathrm{pI}$ range of $4.5-7$. Based on a comparison of changes in plasma protein spot volumes (i.e. the spot volumes at the end of the intervention period (week 8) subtracted the spot volumes at baseline (week 0)) in the samples from subjects in the three intervention groups, a total of eighty-three delta spot volumes were found to differ significantly $(P<0.05$; see Fig. 2 for a $P$ value distribution plot) in abundance depending on the consumed meal type, i.e. changed differently in abundance in the groups during the intervention period. Of these eightythree spots, twenty-three were present in an amount justifying an attempt to identify the proteins by MALDI TOF/TOF MS

Of these twenty-three spots, eighteen were successfully identified (Table 2). Overall, ten spots were found to differ between subjects in the marine trout group and those in the

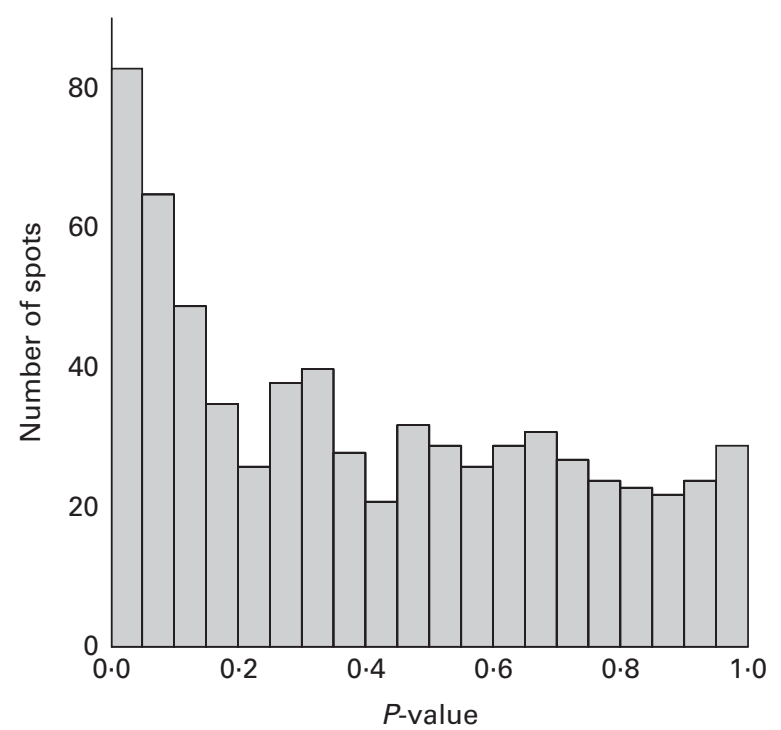

Fig. 2. $P$ value distribution of the comparisons of changes in the spot volumes of 681 plasma protein spots during an 8-week intervention with the marine trout, vegetable trout or chicken diet. Based on the $P$ value distribution, the $q$ value at the $5 \% P$ value cut-off was 0.30 . 


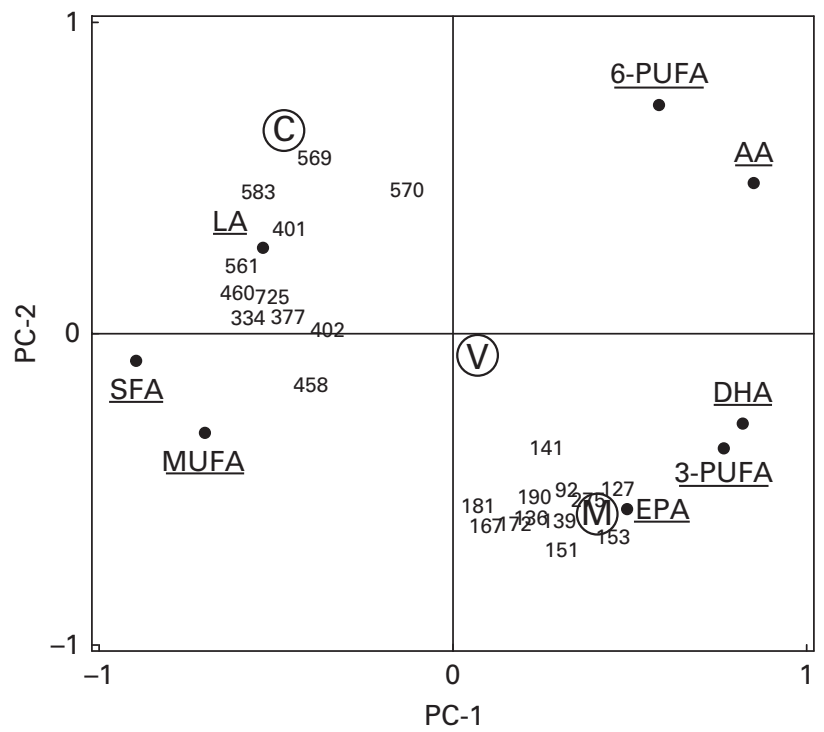

Fig. 3. Principal component analysis visualising correlations between the twenty-three differentially changed protein spots and erythrocyte fatty acid composition. The plot shows the principal components (PC)-1 and (PC)-2 correlation loading scores. The two principal components (PC-1 and PC-2) explained 40 and $21 \%$, respectively, of the total variation in the dataset. Meal groups $(M$, with farmed trout raised on a pure marine diet; $V$, with farmed trout raised on a pure vegetable diet; $\mathrm{C}$, the reference meal of chicken) were included as a pacified categorical variable with no influence on the PCA. 6-PUFA, total $n-6$ PUFA; LA, linoleic acid; AA, arachidonic acid; 3-PUFA, total $n$-3 PUFA.

chicken group, and ten between the vegetable trout group and the chicken group, three of which were common for both trout groups. Only one plasma protein spot differed between the marine trout group and the vegetable trout group. The spots that were affected in both the trout groups were found to be a fibrinogen $\gamma$-chain isomer, cytoplasmic actin 1 and a haemopexin isomer. The seven spots that changed in abundance only in the marine trout group were another fibrinogen $\gamma$-chain and haemopexin isomer, protein $\alpha-1-$ microglobulin/bikunin precursor (AMBP), tetranectin, clusterin, glutathione peroxidase 3 and an isomer of retinolbinding protein 4 ; the seven spots that changed in abundance only in the vegetable trout group were another isomer of haemopexin and retinol-binding protein 4, two different isomers of fibrinogen $\gamma$-chain as well as a spot that were identified as both a fibrinogen $\gamma$-chain isomer and glyceraldehyde-3phosphate dehydrogenase. The single spot that was found to differ significantly in plasma between the two trout groups was identified as complement C1r.

The meal groups were clearly separated in a principal component analysis plot, and the marine trout group had a high covariance with some of the identified protein spots (mainly cytoplasmic actin 1 and isomers of fibrinogen $\gamma$-chain and haemopexin) and $n$-3 LC-PUFA, especially EPA (Fig. 3).

\section{Discussion}

The present study was undertaken to investigate the effects on plasma protein profiles in healthy male subjects, due to a dietary intervention with farmed trout raised on a marine or vegetable feed, on the one hand, and a dietary intervention with chicken, on the other hand. The traditional approach showed an effect of the dietary intervention on erythrocyte fatty acid composition and blood pressure in the trout groups relative to the chicken group; this appeared to be in accordance with the intake of $n$-3 LC-PUFA, but no effects were observed on the plasma lipid profile, pulse wave, heart rate and markers of inflammation or glucose metabolism ${ }^{(19)}$. By adopting a proteomic approach and a comparison of the three intervention groups, we identified a number of plasma proteins that were significantly affected (up- or downregulated) by the dietary treatment.

The plasma proteins that were observed to change in response to the intervention were categorised to be involved in different biological processes including regulation of $\mathrm{Fe}$ homeostasis and haem catabolism and transport, vitamin A transport, oxidative stress, the complement cascade, and blood coagulation and fibrinolysis. The observed plasma proteome changes indicate that fish intake, as such, as well as the feeding regimen of the farmed fish intake may affect these processes.

Among the affected proteins common to the two trout groups were the fibrinogen $\gamma$-chain, retinol-binding protein 4 and haemopexin. As indicated by the names, the latter two are involved in the transport of vitamin A and haem; the fact that these proteins are changed in abundance by fish intake could be indicative of potential interactions with $\mathrm{Fe}$ and vitamin A. This is interesting; such interactions are biologically plausible as well as, to some extent, indicated by a few recent studies. The effects of $n$ - 3 LC-PUFA are, in part, mediated via the activation of peroxisome proliferatoractivating receptors, which are regulated and which interact with retinoic acid receptors ${ }^{(25)}$. Fe has been shown to play a role in the metabolism of $n-3$ PUFA $^{(26)}$. Furthermore, studies on rats and children have indicated the interactions between $n$-3 PUFA deficiency and Fe deficiency ${ }^{(27,28)}$. Fish oil supplementation has been shown to reduce plasma haemopexin relative to sunflower oil supplementation in a study on healthy volunteers $^{(29)}$. In contrast, the spots characterised as fibrinogen and haemopexin were in the present study found to be significantly up-regulated in both the marine trout and vegetable trout groups compared with the reference meal of chicken. However, the difference in response to dietary interventions compared with pharmacological interventions with oil capsules may occur.

Haemopexin is also an acute-phase protein, as is fibrinogen, which by transporting haem to the liver prevent the pro-oxidant and pro-inflammatory effects of haem ${ }^{(30)}$. The plasma concentrations of these proteins increase during insults to the human body such as inflammation. Intake of marine-fed trout was also found to down-regulate the abundance of glutathione peroxidase 3, which is a seleno-dependent enzyme that is believed to be a major component of the human antioxidant defence by protecting, for example, membrane lipids against oxidative damage by detoxification of deleterious oxygen radicals ${ }^{(31)}$. The marine $n-3$ LC-PUFA are highly susceptible to lipid peroxidation due to their high degree of unsaturation $^{(32)}$. However, the pro-oxidative effects may be 
ameliorated by the antioxidant components of the fish flesh. Previous studies have reported conflicting results on the effects of fish oil supplementation on oxidant/antioxidant status in human subjects ${ }^{(33-36)}$. The observed down-regulation of glutathione peroxidase 3 is in accordance with the findings of a previous study on long-term ingestion of fish oil in rats, compared with olive oil or maize oil, which reported reduced activity of glutathione peroxidase in erythrocytes of fish oil-fed rats ${ }^{(37)}$

The $n$-3 LC-PUFA are generally believed to be antiinflammatory and to be dampening immune responses. The complement system plays a vital role in host defence, and represents one of the major effector systems for the immune response. The complement system consists of highly regulated activation steps of proteolytic enzymes and proteins culminating in the membrane attack complex and cell lysis ${ }^{(38)}$. However, inappropriate activation can also contribute to inflammation as observed in various pathological conditions $^{(39)}$. Only a single protein of the complement system, complement factor $\mathrm{C} 1 \mathrm{r}$ that binds to the first protease $\mathrm{C} 1$ initiating the reaction cascade ${ }^{(38)}$, was found to be affected by the current dietary intervention, and tended to increase in abundance in the vegetable trout group compared with the marine trout group. Clusterin, which was affected by the intake of marine-fed trout, has also been described to have regulatory activity on the complement system, as it is a potent inhibitor of the terminal complement assembly, which prevents membrane attachment and reduces complement cytolysis ${ }^{(40)}$.

Our data showed that tetranectin was down-regulated, whereas fibrinogen was up-regulated in subjects who had consumed trout raised on a marine feed. Fibrinogen is a clotting factor and an essential component of the blood coagulation system, and tetranectin is a plasminogen-binding protein that mediates fibrinolysis, and thus dissolves the fibrin meshwork by the activation of plasminogen, and, as a consequence, reduces thrombosis ${ }^{(41)}$. Therefore, our observation is not in agreement with the proposed anti-thrombotic and CVD-reducing effect of fish. Evidence from epidemiological studies suggests that elevated levels of plasma fibrinogen are associated with an increased risk of $\mathrm{CVD}^{(42)}$. Fish oil supplementation has been shown to have a moderate lowering effect on plasma levels of fibrinogen and other coagulation factors, but the degrees vary within healthy individuals, and may depend on fibrinogen levels ${ }^{(43)}$.

Little is known of the mechanisms by which the plasma level of the implicated proteins may be regulated through diet. Some of the proteins that are affected in both trout groups show some differences in the way they are affected, e.g. retinol-binding protein 4 , haemopexin and fibrinogen, and this could potentially be due to dose differences in the intake of $n-3$ LC-PUFA. However, the marine- and vegetable-based trout feed differed in protein source as well as in fat source, and this was associated with some major changes in the amino acid composition of the feed. In contrast, the trout fillets did not differ significantly in their amino acid content ${ }^{(44)}$. It is therefore not very likely that the observed changes were due to the differences in the protein contents of the meals.

The results of the present study indicate that plasma proteomics can be used to reveal insights into the effects of foods on physiological processes and on markers of health. Plasma is the major systemic fluid of the body, and may thus reflect changes in responses in all parts of the body. The use of plasma proteomics is, however, limited both by the dynamic nature of the plasma and thus day-to-day variation in the plasma proteome and by the variability between subjects and methodological variability ${ }^{(45)}$. However, we have attempted to reduce the variability to some extent, by focusing on the changes in individuals over time. Furthermore, many of the proteins that were identified are involved in processes such as blood coagulation and fibrinolysis, the complement cascade and oxidative stress; it would have been a great advantage, if we had also analysed some of the components in the traditional way, so that we could have verified the present results. In order to get a clear separation of the proteins in the $2 \mathrm{DE}$ gels, we had to remove major abundant proteins including apolipoproteins and fibrinogen. These proteins are among the ones that have previously been shown to be affected by dietary fat intake and $n$-3 LC-PUFA ${ }^{(46-48)}$. Inclusion of these proteins in the profiling might have revealed intervention-induced changes in lipid metabolism, especially apoB, which are associated with TAG; these proteins were shown, by traditional methods, contrary to our expectations, to be affected by a daily intake of $n$ - 3 LC-PUFA-rich traditionally farmed trout, raised on a marine-based feed. The study was designed to demonstrate a difference in plasma TAG concentration between subjects in the marine trout and chicken groups ${ }^{(19)}$; however, with the inclusion of twenty men per group, the study had a strong power (80\%) to detect a difference of $0.9 \times \mathrm{SD}$ in any outcome at the $5 \%$ level. However, power calculations are not the primary base for evaluation of the confidence of results from a profiling analysis. Multiple testing is an embedded aspect of all profiling analyses, which one needs to consider either by setting a lower $P$ value cut-off, and $P$ value adjustments, or as we do here by evaluation of the $q$ values. Based on the $P$ value distribution, the $q$ value at a $P$ value cut-off of $5 \%$ was found to be $0 \cdot 30$, indicating that $30 \%$ of the protein spots that differed across the groups are likely to be false positives. It is not possible to identify the false-positive spots, although the risk is higher for those with the highest $P$ values (e.g. clusterin), and significantly lower for those with the lower $P$ values (e.g. cytoplasmic actin 1). The high $q$ value can reflect that the given diets have little influence of the plasma proteome, or that the effect is overshadowed by methodological issues, e.g. variations in protein recovery or the spotting and alignment procedure. The findings of the present study are, therefore, not conclusive, and need verification through further larger studies; however, it has shown new directions for future studies, focusing on randomised controlled trials on the effects of fish intake, e.g. potential interactions with $\mathrm{Fe}$ and vitamins. 


\section{Conclusion}

Based on 2DE and MS analyses, the present proteomic study revealed that a number of plasma proteins may be affected to healthy subjects' advantage through a daily consumption of trout rather than chicken. The proteins that were found to be significantly affected were involved in several pathways, and were believed to play a role in the prevention of CVD. However, consumption of farmed trout, fed on either marine- or vegetable-based feeds, had little impact on the plasma proteome profile.

\section{Supplementary material}

To view supplementary material for this article, please visit http://dx.doi.org/10.1017/S0007114514004152

\section{Acknowledgements}

We gratefully thank Jesper Hallund and Birgitte Overgaard Madsen who helped recruit all the subjects for the study, and did the entire practical work together with our lab technicians and kitchen personnel.

The present study was funded by the Danish Council for Strategic Research.

The authors' contributions are as follows: L. L. and S. B. initiated the intervention study; M. L. R. performed all the proteomic and statistical analyses under the supervision of F. J.; R. L. helped with the spot identification; M. L. R. and L. L. drafted the paper; the other authors commented on the manuscript based on their specific expertise. All the authors read and approved the final manuscript.

None of the authors has any conflicts of interest.

\section{References}

1. Lichtenstein AH, Appel LJ, Brands M, et al. (2006) Diet and lifestyle recommendations revision 2006: a scientific statement from the American Heart Association Nutrition Committee. Circulation 114, 82-96.

2. Kris-Etherton PM, Harris WS \& Appel LJ (2002) Fish consumption, fish oil, omega-3 fatty acids, and cardiovascular disease. Circulation 106, 2747-2757.

3. Bucher HC, Hengstler P, Schindler C, et al. (2002) n-3 Polyunsaturated fatty acids in coronary heart disease: a meta-analysis of randomized controlled trials. Am J Med 112, 298-304.

4. Wang C, Harris WS, Chung M, et al. (2006) n-3 Fatty acids from fish or fish-oil supplements, but not $\alpha$-linolenic acid, benefit cardiovascular disease outcomes in primary- and secondary-prevention studies: a systematic review. Am J Clin Nutr 84, 5-17.

5. Harris WS (1997) n-3 Fatty acids and serum lipoproteins: human studies. Am J Clin Nutr 65, S1645-S1654.

6. Geleijnse JM, Giltay EJ, Grobbee DE, et al. (2002) Blood pressure response to fish oil supplementation: metaregression analysis of randomized trials. $J$ Hypertens $\mathbf{2 0}$, 1493-1499.

7. Mozaffarian D, Geelen A, Brouwer IA, et al. (2005) Effect of fish oil on heart rate in humans - a meta-analysis of randomized controlled trials. Circulation 112, 1945-1952.
8. Xin W, Wei W \& Li XY (2012) Effect of fish oil supplementation on fasting vascular endothelial function in humans: a meta-analysis of randomized controlled trials. PLOS ONE 7 , e46028.

9. Robinson JG \& Stone NJ (2006) Antiatherosclerotic and antithrombotic effects of omega-3 fatty acids. Am J Cardiol 98, 39-49.

10. Zampelas A, Panagiotakos DB, Pitsavos C, et al. (2005) Fish consumption among healthy adults is associated with decreased levels of inflammatory markers related to cardiovascular disease: the ATTICA study. J Am Coll Cardiol 46, $120-124$.

11. Ouellet V, Marois J, Weisnagel SJ, et al. (2007) Dietary cod protein improves insulin sensitivity in insulin-resistant men and women. Diabet Care 30, 2816-2821.

12. Ouellet V, Weisnagel SJ, Marois J, et al. (2008) Dietary cod protein reduces plasma C-reactive protein in insulin-resistant men and women. J Nutr 138, 2386-2391.

13. de Roos B (2008) Proteomic analysis of human plasma and blood cells in nutritional studies: development of biomarkers to aid disease prevention. Expert Rev Proteomics 5, 819-826.

14. Anderson L (2005) Candidate-based proteomics in the search for biomarkers of cardiovascular disease. J Physiol 563, 23-60.

15. Naylor RL, Goldburg RJ, Primavera JH, et al. (2000) Effect of aquaculture on world fish supplies. Nature 405, 1017-1024.

16. Francis G, Makkar HP \& Becker K (2001) Effects of Quillaja saponins on growth, metabolism, egg production and muscle cholesterol in individually reared Nile tilapia (Oreochromis niloticus). Comp Biochem Physiol C Toxicol Pharmacol 129, 105-114.

17. Bell JG, McEvoy J, Tocher DR, et al. (2001) Replacement of fish oil with rapeseed oil in diets of Atlantic salmon (Salmo salar) affects tissue lipid compositions and hepatocyte fatty acid metabolism. J Nutr 131, 1535-1543.

18. Seierstad SL, Seljeflot I, Johansen O, et al. (2005) Dietary intake of differently fed salmon; the influence on markers of human atherosclerosis. Eur J Clin Invest 35, 52-59.

19. Hallund J, Madsen BO, Bugel SH, et al. (2010) The effect of farmed trout on cardiovascular risk markers in healthy men. Br J Nutr 104, 1528-1536.

20. Liu T, Qian WJ, Mottaz HM, et al. (2006) Evaluation of multiprotein immunoaffinity subtraction for plasma proteomics and candidate biomarker discovery using mass spectrometry. Mol Cell Proteomics 5, 2167-2174.

21. Wulff T, Jessen F, Roepstorff P, et al. (2008) Long term anoxia in rainbow trout investigated by $2-\mathrm{DE}$ and MS/MS. Proteomics 8, 1009-1018.

22. Shevchenko A, Wilm M, Vorm O, et al. (1996) Mass spectrometric sequencing of proteins silver-stained polyacrylamide gels. Anal Chem 68, 850-858.

23. Gobom J, Nordhoff E, Mirgorodskaya E, et al. (1999) Sample purification and preparation technique based on nanoscale reversed-phase columns for the sensitive analysis of complex peptide mixtures by matrix-assisted laser desorption/ ionization mass spectrometry. J Mass Spectrom 34, 105-116.

24. Storey JD \& Tibshirani R (2003) Statistical significance for genomewide studies. Proc Natl Acad Sci US A 100, 9440-9445.

25. Al Tanoury Z, Piskunov A \& Rochette-Egly C (2013) Vitamin A and retinoid signaling: genomic and nongenomic effects. J Lipid Res 54, 1761-1775.

26. Krajcovickova-Kudlackova M \& Dusinska M (2004) Polyunsaturated fatty acid plasma content in groups of general population with low vitamin B-6 or low iron serum levels. Ann Nutr Metab 48, 118-121. 
27. Baumgartner J, Smuts CM, Malan L, et al. (2012) Effects of iron and $n-3$ fatty acid supplementation, alone and in combination, on cognition in school children: a randomized, double-blind, placebo-controlled intervention in South Africa. Am J Clin Nutr 96, 1327-1338.

28. Baumgartner J, Smuts CM, Malan L, et al. (2012) Combined deficiency of iron and $n-3$ fatty acids in male rats disrupts brain monoamine metabolism and produces greater memory deficits than iron deficiency or $n-3$ fatty acid deficiency alone. J Nutr 142, 1463-1471.

29. de Roos B, Geelen A, Ross K, et al. (2008) Identification of potential serum biomarkers of inflammation and lipid modulation that are altered by fish oil supplementation in healthy volunteers. Proteomics 8, 1965-1974.

30. Tolosano E, Fagoonee S, Morello N, et al. (2010) Heme scavenging and the other facets of hemopexin. Antioxid Redox Signal 12, 305-320.

31. Papp LV, Lu J, Holmgren A, et al. (2007) From selenium to selenoproteins: synthesis, identity, and their role in human health. Antioxid Redox Signal 9, 775-806.

32. Song JH, Fujimoto K \& Miyazawa T (2000) Polyunsaturated $n-3$ fatty acids susceptible to peroxidation are increased in plasma and tissue lipids of rats fed docosahexaenoic acid-containing oils. J Nutr 130, 3028-3033.

33. Higdon JV, Liu J, Du SH, et al. (2000) Supplementation of postmenopausal women with fish oil rich in eicosapentaenoic acid and docosahexaenoic acid is not associated with greater in vivo lipid peroxidation compared with oils rich in oleate and linoleate as assessed by plasma malondialdehyde and F2-isoprostanes. Am J Clin Nutr 72, 714-722.

34. Wander RC \& Du SH (2000) Oxidation of plasma proteins is not increased after supplementation with eicosapentaenoic and docosahexaenoic acids. Am J Clin Nutr 72, 731-737.

35. Meydani M, Natiello F, Goldin B, et al. (1991) Effect of longterm fish oil supplementation on vitamin E status and lipid peroxidation in women. $J$ Nutr 121, 484-491.

36. Harats D, Dabach Y, Hollander G, et al. (1991) Fish oil ingestion in smokers and nonsmokers enhances peroxidation of plasma lipoproteins. Atherosclerosis 90, 127-139.
37. Miret S, Saiz MP \& Mitjavila MT (2003) Effects of fish oil- and olive oil-rich diets on iron metabolism and oxidative stress in the rat. BrJ Nutr 89, 11-18.

38. Porter RR \& Reid KB (1978) The biochemistry of complement. Nature 275, 699-704.

39. Morgan BP \& Harris CL (2003) Complement therapeutics; history and current progress. Mol Immunol 40, 159-170.

40. McDonald JF \& Nelsestuen GL (1997) Potent inhibition of terminal complement assembly by clusterin: characterization of its impact on C9 polymerization. Biochemistry 36, 7464-7473.

41. Murray V, Norrving B, Sandercock PA, et al. (2010) The molecular basis of thrombolysis and its clinical application in stroke. J Intern Med 267, 191-208.

42. Kamath S \& Lip GYH (2003) Fibrinogen: biochemistry, epidemiology and determinants. Q J Med 96, 711-729.

43. Vanschoonbeek K, Feijge MAH, Paquay M, et al. (2004) Variable hypocoagulant effect of fish oil intake in humans: modulation of fibrinogen level and thrombin generation. Arterioscler Thromb Vasc Biol 24, 1734-1740.

44. Timm-Heinrich M, Eymard S, Baron CP, et al. (2013) Oxidative changes during ice storage of rainbow trout (Oncorbynchus mykiss) fed different ratios of marine and vegetable feed ingredients. Food Chem 136, 1220-1230.

45. Griffiths HR \& Grant MM (2006) The use of proteomic techniques to explore the holistic effects of nutrients in vivo. Nutr Res Rev 19, 284-293.

46. Iggman D, Gustafsson IB, Berglund L, et al. (2011) Replacing dairy fat with rapeseed oil causes rapid improvement of hyperlipidaemia: a randomized controlled study. I Intern Med 270, 356-364.

47. Hartweg J, Farmer AJ, Holman RR, et al. (2009) Potential impact of omega-3 treatment on cardiovascular disease in type 2 diabetes. Curr Opin Lipidol 20, 30-38.

48. Bladbjerg EM, Larsen TM, Due A, et al. (2010) Long-term effects on haemostatic variables of three ad libitum diets differing in type and amount of fat and carbohydrate: a 6-month randomised study in obese individuals. Br J Nutr 104, 1824-1830. 